\title{
Nonviolent Communication ( NVC) training increases empathy in baccalaureate nursing students: A mixed method study
}

\author{
Marcianna Nosek, Elizabeth Gifford, Brendan Kober \\ School of Nursing \& Health Professions, University of San Francisco, San Francisco, USA. \\ Correspondence: Marcianna Nosek. Address: School of Nursing \& Health Professions, University of San Francisco, San \\ Francisco, USA. Email: mnosek@usfca.edu
}

Received: February 13, 2014

Accepted: July 16, 2014

Online Published: July 29, 2014

DOI : $10.5430 /$ jnep.v4n10p1

URL: http://dx.doi.org/10.5430/jnep.v4n10p1

\begin{abstract}
Background: Ineffective communication among healthcare team members is associated with decreased collaborative efforts and adverse patient outcomes. The impact of empathy on collaboration with colleagues and patient interaction has been previously demonstrated. Studies have yet to measure the impact of (Nonviolent Communication [NVC]) on empathy in nursing students.

Purpose: The purpose of this mixed methods study was to test a communication intervention (NVC) with baccalaureate student nurses to examine its effect on empathy.

Methods: A mixed methods single group pre/post test design incorporating the Interpersonal Reactivity Index (IRI) to measure empathy was used. A paired samples $t$ test was calculated to compare means scores pre and post intervention. One-way ANOVA was used to examine between group differences. Interpretive methods were used to analyze qualitative data collected via journal entries during the training and focus groups immediately following and 2 years post intervention.

Results/Findings: Quantitative results revealed an increase in empathy (69.1 to 71.4, $p=.037)$ post training. Qualitative analyses demonstrated positive impact of NVC in empathizing with self and others. Clinical impact was especially noted when working with psychiatric patients.

Conclusion: Incorporating NVC into nursing education could feasibly prevent future hardship as students advance their nursing careers. Further research may be needed to capture the larger impact that NVC could have on nurses and nursing students.
\end{abstract}

\section{Key words}

Nonviolent Communication, Empathy, Intervention, Qualitative, Nursing students

\section{I ntroduction}

Ineffective communication among healthcare team members is associated with decreased collaborative efforts and adverse patient outcomes ${ }^{[1-5]}$. In a recent survey of nurses, $60 \%$ reported verbal abuse, $26 \%$ reported physical abuse, and $23 \%$ reported sexual harassment or hostile environment in the workplace ${ }^{[1]}$. Conflict, an inevitable human experience may 
impair communication, and ultimately jeopardize collaboration ${ }^{[6-8]}$. Yet, proper and timely management of conflict can prevent harmful consequences ${ }^{[6-8]}$. Effective skills to negotiate and manage conflict, and enhance cooperation and collaboration need to be developed in healthcare team members ${ }^{[1,3,4,6-13]}$.

Empathy, the capacity to understand and share in another's emotional experience or situation may lead to an increase in emotional intelligence, as well as positively affect communication skills of nurses ${ }^{[13-16]}$. Empathy in healthcare as a concept has been studied with attempts to understand its theoretical axioms ${ }^{[16]}$. Nurses' therapeutic interaction with patients not only includes the ability to perceive others' experiences but also the capacity to effectively communicate these perceptions to their patients ${ }^{[16]}$. Moreover, a lack of empathy has been associated with violent behavior ${ }^{[17]}$.

Efforts to foster empathy, and enhance communication and conflict resolution during nursing training may facilitate collaboration among nurses in the workplace. In addition, student nurses are confronted with challenges in dealing with emotional situations with their patients' illnesses, as well as demanding healthcare environments, which may be very foreign to the beginning nurse. In-coming freshman nursing students especially may have had very little training in empathy building skills.

The majority of literature on collaboration in healthcare report descriptive accounts of ineffective communication and conflict resolution between healthcare team members ${ }^{[6-11]}$. However, few report on tested interventions ${ }^{[12]}$. A body of literature exists reporting on various programs tested to enhance empathy in nursing students or clinical nurses with mixed results ${ }^{[18-21]}$. The purpose of this mixed methods study was to test a communication skill building intervention (Nonviolent Communication $[\mathrm{NVC}]$ ) with baccalaureate student nurses to examine its ability to increase empathy. A successful communication training intervention could eventually be considered an integral part of nursing education curricula in order to build nurses' capacity to communicate empathically with patients and colleagues. This, in turn, could potentially aid future nurses to be transformational leaders and effectively manage conflict in the workplace.

\subsection{Background/ literature review}

Researchers have demonstrated that enhanced empathy positively impact nurses' experiences of their interactions with patients and colleagues, including their ability to communicate and manage conflict more effectively. Nonviolent Communication (NVC) ${ }^{[22,23]}$, a method of compassionate communication has yet to be tested with nurses; however, preliminary pilot studies and experts in the field have reported enhanced abilities to communicate effectively and compassionately in various settings with the use of $\mathrm{NVC}^{[24-31]}$. The following section reports on the literature on empathy in nursing, and nonviolent communication in general and in healthcare.

\subsubsection{Empathy}

Williams \& Stickley ${ }^{[18]}$ conducted a literature review from nursing and counselling sources to develop an understanding of the meaning of empathy especially as it related to nurse education and practice. Citing Carl Rogers, they described a four stage empathic process: The affective is when the therapist 'feels' the emotions of the client. This is followed by the cognitive intention to gain insight into the meaning behind the emotion while suspending their own internal point of reference $^{[18]}$. The third stage is the behavioral component emphasizing the communication of an empathic response. The authors ${ }^{[18]}$ emphasized that this is the most focused on step in the research as it is easier to measure, and that this may not necessarily need to be verbally communicated. They cited an additional stage proposed by Jones and supported by Nosek ${ }^{[31]}$ that the empathy received by one may aid in the others' self understanding. Williams \& Stickley ${ }^{[18]}$ also warn against reducing the experience of empathy to stages and suggest that it may serve us better to tune more into the bodily experience of the phenomenon as more of a 'felt sense' proposed by Gendlin. They continue with the argument that one must be 'in tuned' with their own experiences as a means to enhance one's capacity for empathy toward others ${ }^{[18]}$. Moreover, they strongly support the need for nursing education to include methods for students to develop self awareness ${ }^{[18]}$. 
In an attempt to enhance baccalaureate students' ability to empathize with psychiatric patients, Webster ${ }^{[21]}$ conducted a mixed methods study that incorporated the use of creative reflective journals during their 14 week psychiatric clinical rotation. The Interpersonal Reactivity Index (IRI) ${ }^{[32]}$ was used to compare empathy scores of the students who journaled (n $=29)$ versus the control group $(n=44)$ who completed a traditional clinical rotation ${ }^{[21]}$. No differences in empathy scores pre and post clinical rotation were noted in either group ${ }^{[28]}$. However, four themes were identified in the qualitative analysis: having expectation, building relationships, changing perceptions, and gaining understanding ${ }^{[21]}$.

Empathy has also been examined as a component of effective leadership skills ${ }^{[33]}$. Aligned with empathy as a component of emotional intelligence, Gunther et al. ${ }^{[33]}$ aimed to describe any associations between leadership styles and empathy. They defined leadership as "a broad competency that embraces two dimensions: managing oneself and handling one's relationships with others" ${ }^{\text {[33] }}$. Their aim to test the three popular styles of leadership: transformational, transactional and laissez faire, with empathy scores resulted in weak, but statistically significant associations between empathy and elements of transformational leadership styles ${ }^{[33]}$. A transformational leader recognizes the importance of interpersonal relationships.

The above research supports the role of empathy in enhancing nurses' experiences of connecting with patients. In addition, it demonsrates that empathy, as an important component of emotional intelligence, has potential for affecting positive changes in interpersonal relations with coworkers, thus enhancing transformational leadership and job retention, and decreasing conflict in the workplace.

\subsubsection{Nonviolent Communication}

The intervention, Nonviolent Communication (NVC) is a method of communication developed by Dr. Marshall Rosenberg ${ }^{[22,23]}$, a psychologist, educator, and global conflict mediator, to encourage a compassionate response to emotions, which fosters empathy in lieu of blame toward self and others. NVC is based on the theory that we, as humans have universal needs, and that when those needs are met effectively, we experience satisfactory feelings, such as joy, peace, and contentedness ${ }^{[22,23]}$. When needs are not being met, adverse feelings such as frustration, anger, fear, etc. manifest ${ }^{[22,23]}$. Dr. Rosenburg ${ }^{[22,23]}$ suggests a 4 stage process to enable effective empathic, and also referred to as compassionate communication, and conflict management. First, an objective observation is made of a situation while avoiding judgment; second, the emotional response to the situation is noted; third, an investigation is made regarding what needs may or may not have been met; and last, a non demanding request is presented ${ }^{[22,23]}$. NVC can be used as a means of expressing oneself and as a means to understanding others' communication efforts, which are sometimes compromised ${ }^{[22,23]}$.

Nonviolent Communication has been proposed as a useful communication tool in various settings and with various populations globally, including its use in primary and secondary schools for conflict resolution ${ }^{[26]}$, partnership learning communities in education ${ }^{[26]}$, and because it was proposed to be well aligned with humanizing practices and doctrine of the clergy, in theological education ${ }^{[28]}$. However, overall empirical data on the effectiveness of NVC training is lacking, and very little has been tested in the healthcare arena ${ }^{[24,25]}$.

Rosenburg \& Molho ${ }^{[24]}$ conducted a preliminary descriptive examination of Nonviolent Communication use in a healthcare setting. Examples of successful use of NVC with patient-provider interactions were reported, as well as positive physician-hospital administrator interfaces dealing with the introduction of new policies that frequently are met with resistance ${ }^{[24]}$. They concluded that the very "intention of this process is to connect compassionately to other human beings before blaming, correcting, or educating" ${ }^{[24]}$.

Marlow and colleague's ${ }^{[25]}$ research on the use of NVC with parolees demonstrates the only empirically tested NVC intervention. Their pre/post test quasi-experimental design revealed an increase in empathy scores in previously incarcerated men as measured by the BEES Empathy Tool (.49 to $.93 ; p=.010)^{[25]}$. In addition, participants shared rich narratives of enhanced empathic listening and successful conflict management ${ }^{[25]}$. No studies on NVC and nurses have 
been published to date, but in an opinion piece, Sitman suggested the use of NVC as a creative means to "foster positive resolution" in nursing workplace situations that may spark defensive, angry responses ${ }^{[34]}$.

Chung \& $\mathrm{Kim}^{[29]}$ presented findings at a professional nursing conference from a pilot study conducted on the effects of a Nonviolent Communication program for hospital nurse managers in Korea. Even though there were no significant changes in empathic ability and self-efficacy of communication amongst the unit managers before and after the NVC intervention, the researchers found that levels of facilitative communication were significantly increased in the experimental group compared to the control group post training ${ }^{[29]}$.

In an intriguing discussion of the use of Nonviolent Communication for international relations, KÖK ${ }^{[30]}$ analyzed the principles of NVC through the lens of Human Needs Theory in order to explain the assumptions behind NVC. He described how Human Needs Theory examines the core source of conflict, and quotes John Burton, a social theorist who proposed that Human Needs Theory could facilitate an objective understanding of how political and cultural differences result in conflict and also how the resolution of conflict can be manifested via this understanding ${ }^{[30]}$. As a researcher of conflict resolution, he has found that "the importance of human needs is now generally recognized by conflict theorists" ${ }^{[30]}$. KÖK supports the use and value of NVC and also emphasizes the need to assimilate the process of using the technique so it becomes a natural response, something that would evolve naturally over time and repetitive use ${ }^{[30]}$.

Testing of Nonviolent Communication interventions is sparse, but the few studies examined have demonstrated positive results in various populations including healthcare providers. Researchers have written on its theoretical axioms explaining how NVC may facilitate objective understanding, and have supported its impact on enhancing empathy and facilitative communication, and reducing conflict. No studies to date have examined the impact of NVC on empathy in nursing students.

\section{Methods}

A mixed methods quasi experimental design was used incorporating a single group pre/post test analysis along with journal entries during the training, and focus groups immediately following and 2 years post intervention. The intervention was a training in Nonviolent Communication (NVC) conducted by two professional and experienced NVC trainers. Quantitative analyses were driven by the following hypothesis: NVC training will increase empathy in undergraduate nursing students. Interpretive methods were used to analyze qualitative data and are presented thematically, and supported by exemplars and thick description of participants' narratives ${ }^{[35,36]}$.

\subsection{Sample recruitment}

Baccalaureate nursing students attending a professional nursing course in their first or second semester at a United States private Catholic university on the west coast of California, were invited to participate. All students in the professional nursing course received the training; however, only those who consented to participate in the study completed pre and post intervention surveys with the option to submit on-line journal entries and attend a focus group at the end of the semester and two years later following clinical rotations. Inclusion criteria included students who were eighteen years or older, currently attending the professional nursing course, and proficient in English. A statistical power analysis was calculated using $G$ Power ${ }^{[37]}$ to determine the sample size needed for robust analyses. Power equal to .80 was used as is advised when the exact figure is unknown. In a difference of means analysis with $\alpha=.05$, effect size $=.80$, and power $=.80$, a sample size of at least 26 was needed.

\subsection{Ethical considerations}

All students attending the professional nursing course were explained details of the study and for those who agreed to participate, written informed consent was obtained prior to completing baseline questionnaires. In order to avoid the possibility of coercion and to maintain confidentiality, the instructor of the course was not the PI was not present when 
students completed consents and in-class questionnaires and did not know who were actual participants in the study. In order to compensate for out of class time, participants were offered the chance to enter a lottery for a $\$ 25$ gift certificate to a technology store for the completion of the on-line surveys and attending a focus group, and $\$ 5$ coffee gift certificates were offered for each journal entry up to four.

\subsection{Data collection procedures and measures}

\subsubsection{Study instruments}

The quantitative portion of the study incorporated the use of one instrument: the Interpersonal Reactivity Index (IRI) ${ }^{[32,38]}$ measuring empathy. Psychometrics of the instrument has been well documented ${ }^{[32,38]}$ and has been used extensively in nursing research and with university students ${ }^{[18,19,21,32,38-40]}$.

The IRI is a 28 -item multidimensional inventory that measures four separate dimensions of empathy ${ }^{[32,38]}$. The instrument was designed to capture individual variations in both cognitive and affective foundations of empathy ${ }^{[32]}$. The following Cronbach's alpha coefficients for both males and females, respectively, have been recorded for each 7-item scale: Perspective Taking Scale (alpha $=.75, \& .78)$; Fantasy Scale (alpha $=.78 \& .75)$; Empathic Concern Scale (alpha $=.72$ \& .70); and Personal Distress Scale (alpha $=.78 \& .78)^{[32]}$. The two cognitive measures, Perspective Taking and Fantasy measure the ability of one to adopt others' perspectives in real-life situations, and the tendency to identify with fictional characters, respectively ${ }^{[32,38]}$. The two affective measures, Empathic Concern, and Personal Distress measure one's ability to feel warm, compassion, and concern for others who are undergoing negative experiences, and the extent to which one experiences fear, anxiety and discomfort when witnessing others' negative experiences, respectively ${ }^{[32,38]}$.

The IRI which is a paper survey was administered before the intervention was initiated and on the day informed consent was obtained which was Class 2 of the professional nursing course, and again, post training on Class 7. In addition, participants completed a structured sociodemographic questionnaire, which included questions on age, gender, ethnicity, education, religion, transfer or 4 year student, and GPA.

\subsubsection{I ntervention}

The intervention included two, one-hour and forty-five minute NVC training sessions by two professional NVC trainers with similar levels of experience and who together developed the curriculum to be taught at each session. The professional nursing course had 8 sections of students who met every other week, and the training was conducted on Classes 3 and 4 of the semester for each section. The first training session was focused on teaching students skills in expressing feelings, needs, and requests to others and also included methods to enhance self empathy. The second training session focused on helping the students gain understanding of how to interpret others' feelings and needs, with the intention of enhancing empathy toward others. Follow-up support was given through feedback to those who submitted on-line journal entries. Role playing of NVC practice was used extensively during the training period. These tactics were employed to increase skill acquisition, self reflection, and self awareness.

\subsubsection{Statistical analyses}

Quantitative data were analyzed using IBM SPSS software $20^{\text {th }}$ edition. A paired samples $t$ test was calculated to compare the mean pretest score to the mean final score for each dependent variable. Statistical significance was determined on a one-tailed alpha level of 0.05 . Only participants with both pre and post test scores were included in the analyses. One-way ANOVA was also calculated to examine between-group differences.

\subsubsection{Qualitative data collection and analysis}

Narrative sources for the qualitative findings include: student on-line journaling during training using Blackboard ${ }^{\mathrm{TM}}$, the university Learning Management System; focus groups $\times 6$ immediately after training; email written accounts 2 years post 
training; and focus groups $\times 2,2$ years post training. The journals were created exclusively for the study and only the PI, research assistant, and trainers had access to them. Participants were unable to read each other's entries. Feedback was given by the trainers and/or the PI on all journal entries.

The following questions were asked during the immediate post training focus groups to stimulate discussion: What was your overall take away of learning NVC? How has NVC affected your ability to understand the emotions and needs of yourself and others? How has your understanding of empathy changed as a result of learning NVC? What aspect of NVC has contributed to your ability to resolve conflict? How do you see using NVC helpful as a nurse, or as a nursing student? What obstacles have you experienced using NVC?

All digitally recorded data including post intervention focus groups were transcribed verbatim by an experienced transcriber. Transcriptions were then organized and coded, and narrative and thematic analyses were performed ${ }^{[35,36]}$.

\section{Quantitative results}

\subsection{Participant characteristics}

A total of 74 students $(\mathrm{N}=74)$ completed the baseline demographic questionnaire. The average age was $19(\mathrm{SD} \pm 2.3)$ with $89 \%$ female $(\mathrm{n}=67)$, and $9 \%$ male $(\mathrm{n}=7)$. Ethnicity breakdown includes $28.1 \%$ Asian $(\mathrm{n}=21), 41.9 \%$ White $(\mathrm{n}=31)$, $13.4 \%$ Latino $(\mathrm{n}=10)$, and $9.5 \%$ Other $(\mathrm{n}=7)$. The average GPA of the student was $3.42(\mathrm{SD} \pm 0.4)$. Eighty-five point one percent $(n=63)$ were freshman standing with $12.2 \%(n=9)$ sophomores. Around a quarter $(23 \%, n=17)$ claimed to be transfer students. Table 1 includes demographic information for the participants at baseline $(\mathrm{N}=74)$ and for those who completed the pre and post IRI $(\mathrm{n}=55)$.

Table 1. Demographics at Baseline $(\mathrm{N}=74)$, for participants completing IRI $(\mathrm{n}=55)$

\begin{tabular}{|c|c|c|}
\hline & At Baseline $(\mathrm{N}=74)$ & Completed IRI $(\mathrm{n}=55)$ \\
\hline Age (mean \pm SD) & $19 \pm 2.3$ & $19 \pm 2.2$ \\
\hline \multicolumn{3}{|l|}{ Gender (n, \%) } \\
\hline Male & $7(9 \%)$ & $6(10.9 \%)$ \\
\hline Female & $67(89 \%)$ & $49(89.1 \%)$ \\
\hline \multicolumn{3}{|l|}{ Religion } \\
\hline None & $10(13.5 \%)$ & $8(14.5 \%)$ \\
\hline Christian & $11(14.9 \%)$ & $10(18.2 \%)$ \\
\hline \multicolumn{3}{|l|}{ (non Catholic) } \\
\hline Catholic & $37(50 \%)$ & $27(49.1 \%)$ \\
\hline Other & $12(16.4 \%)$ & $8(14.5)$ \\
\hline GPA (mean \pm SD) & $3.42 \pm .4$ & $3.47 \pm .4$ \\
\hline \multicolumn{3}{|l|}{ Ethnicity (n, \%) } \\
\hline Asian & $21(28.1 \%)$ & $14(25.2 \%)$ \\
\hline White & $31(41.9 \%)$ & $27(49.1 \%)$ \\
\hline Latino & $10(13.4 \%)$ & $7(12.6 \%)$ \\
\hline Other & $7(9.5 \%)$ & $5(9 \%)$ \\
\hline \multicolumn{3}{|l|}{ Semester (n, \%) } \\
\hline Freshman & $63(85 \%)$ & $46(83.6 \%)$ \\
\hline Sophomore & $9(12.2 \%$ & $9(16.3 \%)$ \\
\hline \multicolumn{3}{|l|}{ Transfer Student } \\
\hline Yes & $17(23 \%)$ & $14(25.5 \%)$ \\
\hline No & $56(76 \%)$ & $41(74.5 \%)$ \\
\hline
\end{tabular}




\subsection{Empathy}

A total of 55 students completed the paper IRI Empathy survey both pre and post intervention with a mean increase in scores from $69.1(\mathrm{SD} \pm 12.3)$ pre NVC training to $71.4(\mathrm{SD} \pm 12.3)$ post training $(t=-1.828 ; p=.037)$. See Table 2 for details including breakdown of subscales and ranges. One- way ANOVA demonstrated no differences between groups vis-a-vis ethnicity, age, GPA, semester, or transfer status. However, gender differences were noted in IRI Total Scores, both pre (males: $59.5 \pm 4.3$, females: $70.2 \pm 1.7 ; F(1,53)=4.34, p=.025$ ) and post intervention (males: $61.3 \pm 4.6$, females: $72.5 \pm 1.6 ; F(1,53)=4.81, p=.030)$. The attrition rate post training for the IRI was $24 \%$.

Table 2. Empathy (IRI) Total and Subscales: Perspective taking, Fantasy, Empathic concern, \& Personal distress Paired Samples $T$ Test $(\mathrm{n}=55)$

\begin{tabular}{|c|c|c|c|c|c|}
\hline \multicolumn{6}{|c|}{ Pre \& Post Intervention of NVC Training } \\
\hline & \multirow{2}{*}{ Mean \pm SD } & \multicolumn{2}{|c|}{ Range } & \multirow{2}{*}{$t$ statistic } & \multirow{2}{*}{$p$ value } \\
\hline & & Minimum & Maximum & & \\
\hline \multicolumn{6}{|l|}{ IRI Total } \\
\hline Pretest & $69.1 \pm 12.3$ & 43 & 97 & -1.828 & $.037 *$ \\
\hline Posttest & $71.4 \pm 12.3$ & 46 & 98 & & \\
\hline \multicolumn{6}{|l|}{ Subscales } \\
\hline \multicolumn{6}{|c|}{ Perspective taking } \\
\hline Pretest & $19.1 \pm 4.6$ & 8 & 28 & -1.481 & .073 \\
\hline Posttest & $19.8 \pm 4.4$ & 11 & 28 & & \\
\hline \multicolumn{6}{|l|}{ Fantasy } \\
\hline Pretest & $17.7 \pm 5.2$ & 4 & 28 & -1.566 & .061 \\
\hline Posttest & $18.6 \pm 5.2$ & 8 & 28 & & \\
\hline \multicolumn{6}{|c|}{ Empathic concern } \\
\hline Pretest & $21.8 \pm 4.5$ & 6 & 28 & -.878 & .172 \\
\hline Posttest & $22.2 \pm 3.6$ & 13 & 28 & & \\
\hline \multicolumn{6}{|c|}{ Personal distress } \\
\hline Pretest & $10.5 \pm 4.9$ & 1 & 23 & -.495 & .312 \\
\hline Posttest & $10.7 \pm 4.7$ & 1 & 23 & & \\
\hline
\end{tabular}

\section{Qualitative findings}

Students reported positive experiences using NVC in various settings and situations. Although some spoke of the challenges using it, they mostly relayed the benefits, and admitted that the challenges stemmed from needing to practice it more so it would become more natural. Overall, participants reported a sense of increased empathy and ability to connect with others, and resolve conflict and improve communication through the use of NVC.

The interpretation of findings was conducted with constructs of empathy kept in the foreground. The ability to identify and understand emotions in self and others demands empathic concern and facilitative cognitive reasoning, all core constructs of empathy. Table 3 lists direct quotes shared in response to discussion questions posed in the six focus groups immediately post training, including hypothetical situations working with patients. Stories that were also shared via emails received at the time the focus groups were being set up were used for the analyses. Narratives shared via journals are published elsewhere (see Nosek) ${ }^{[31]}$.

The following exemplary stories are divided into Personal Experiences with subheadings of Intrapersonal and Interpersonal, and Professional Experiences, which are presented under the subheadings, Working with Children, and Working with Patients. 


\subsection{Personal experiences}

\subsubsection{I ntrapersonal}

Students reported the use of NVC toward self less often than they had reported its use in understanding and/or communicating with others. However, it was acknowledged that the act of empathy for oneself is beneficial even though at times difficult to tune into. Some expressed that they have started to explore why they may be feeling one way or another, and which needs were or were not being met. In this next excerpt, an increase in insight was noted when the student was asked how self empathy may have been increased as a result of learning NVC:

Before, if I was mad, I would just kind of feel, okay I'm frustrated, but I wouldn't really look at like why I was mad. And now I can sit down and say, okay maybe I'm stressed out, maybe I have not had enough sleep and then I can work on that to improve myself...

This student expresses an enhanced understanding of her emotions which leads to a sense of empowerment, as she becomes an agent to actively manage her feelings in order to get her needs met. She spoke of how before, she would be caught up in her emotions, and now, she has a tool to assess her emotional experience cognitively by reflecting on what may be going on and find ways to remedy it proactively. Understanding the needs of self is an important aspect of NVC, in and of itself, and is a key component in developing the ability to understand the needs of others. Pausing and reflecting contributes to the ability to empathize and assuage reacting in a way that may have negative consequences.

\subsubsection{I nterpersonal}

Most of the benefits shared about NVC were directed toward interpersonal relationships. Students shared many stories and sentiments about how NVC helped them navigate situations between themselves and parents, roommates, boyfriends and girlfriends, and teachers. They shared an increased ability to recognize, or at least, consider what the other person may be feeling and needing during a time of conflict. When asked what was most helpful about learning NVC, many reported that having a framework, structure, or steps to follow actually gave them a concrete way to identify, understand emotions and needs of others, and apply empathy in a range of situations.

One student relayed that NVC was helpful to her in listening to others without putting herself into the picture. She shared:

...When people would tell me their problems, I was one of the people who would always try to compare it to my life. And $[\mathrm{NVC}]$ really helped me in approaching problems, and being able to see the underlying meaning, and then being able to just talk to them about what they need, instead of 'oh well, one time that happened to me too...'

The ability for this student to remove herself from the experience when another is speaking is a cornerstone to empathic listening. She attributes this new skill to the element of NVC that suggests the benefit of tuning into the needs of others, to help them understand themselves more effectively. This is a key aspect of therapeutic communication, and demonstrates an increase in empathy.

Many students shared the success of using NVC with conflicts they have with roommates. This narrative captures its usefulness in a common situation that students are faced with living with others who are strangers.

When we first moved in...there was a lot of argument and a lot of like escalating between two guys trying to be like the power of the house... until just one day I started just keeping a little more quiet, just letting them talk...I would just say... Why did I upset you so much? Let me understand what you're feeling... And that's really helped us a lot.

This student brings up important elements of interpersonal relations when a power struggle is involved. He speaks of a turning point when he decides to pause and ask questions that show his interest in wanting to understand his roommate. This example demonstrates the effectiveness of NVC even when just one person is familiar with it as the roommate became receptive once a different approach was taken. In times of conflict, it is challenging to regulate one's emotions, and tune into the other to gain perspective from the other's viewpoint. This ability reflects a higher level of empathic concern for another. 
Table 3. Student Responses to Specific Questions Posed in Immediate Post Training Focus Groups $(\times 6)$

\section{Overall take away of learning NVC? Or How has NVC affected your ability to understand the emotions and needs of yourself and others?}

1."Attention to word choice...instead of blurting out the first thing that comes to mind"

2. "What are they really feeling? I caught myself thinking about that a lot."

3. "I feel like it's going to be helpful to kind of center yourself."

4. "I found it really useful with understanding others."

5. "It's been really helpful for me to understand why I'm feeling sort of ways."

6. "I really use it a lot figuring how [my roommates] are feeling...I like it pretty good."

7. "I felt like it was easier to help [friends] work through [their problems]."

8. "It helps [others] to just talk through it and have somebody who recognizes what they're feeling."

9. "It helps you learn that you don't have to try to fix everyone's problems."

10. "Helped me understand the way other people are."

11. "Helped me understand what I wanted more out of a certain situation."

12 "I actually used it on my roommate when we were having disputes and I would say,'oh, why is she feeling this way?' And then I would say 'oh, why was I feeling this way?"”

13. "Thinking a different way. Trying to understand people."

14. "It would just make any conflict easy to deal with in life."

15. "Knowing that I could have applied it in places, makes me feel that I'm making the connection. It's fully useable in every situation."

16. "I just felt like I can recognize my feelings, and then I can recognize their feelings. And we can come to an agreement."

17. "I guess I'm more aware. Like I knew I was upset, but I didn't know what exactly had made me feel that way sometimes."

18. "Just controlling your emotions."

19. "Just know what to do, and what is right."

20. "We learn that there's another way to do things."

How has your understanding of empathy changed as a result of learning NVC?

1."My definition of empathy hasn't necessarily changed, but my understanding and ability to put it into practice has."

2. "...You can get more information out of it, than the sympathy term for empathy."

3. "Just so they feel like that you understand them instead of just feeling sorry for them."

4. "I think empathy for yourself is also really helpful."

5. "I think that I take more time now to respond to someone and kind of see the problem or the situation from their perspective."

6. "I think it's just like putting yourself in the other person's shoes, but also like getting your feelings across to them as well."

7. "I just notice myself saying, "Like I understand that you need blank, because you need ..."”

8. "I'm now the calm one that kind of brings the voice of reason."

9. "Not just be one-sided. To know the other side. It kind of like holds me back before I say something. Like, I really think about it before I put my feelings out there."

10. "I kind of like take a step back and think, okay, what are they thinking right now?"

11. "Well, I guess before I knew what empathy was, but I didn't really know how to go about it. I think it taught me more like step by step how to learn to empathize for other people."

12. "I do know what it is now, after going through this class...I know how it is now. I clearly know."

What aspect of NVC has contributed to your ability to resolve conflict?

1. "I think the fact that there was like a formula with it, and like a thought process. It helped me articulate what I'm trying to say more."

2. "I think it was the process that really helped me, because before I got really angry like when I shout. But then after...you have to take a step back and look at the whole, the big picture."

3. "What do I need...? What do they need? That is what I think helped me the most. Instead of just, 'Oh my God, what am I going to do?"”

4. "It's the same thing you can go back to every time. . . it's always going to help you."

5. "The process just gives me something to work with other than when you're feeling all these emotions kind of run around like chicken with its head cut off."

6. "I like the structure and order if you're in a situation where you're just swimming in a sea of emotions. Not only does this give you a starting place, but it just gives you a whole roadmap for you to follow."

How do you see using NVC helpful as a nurse, or as a nursing student? (hypothetical)

1. "There being a lack of communication between a nurse especially, at their (inaudible) (inaudible) or whatever. I feel like that would come in handy a lot. Just because it helps you communicate what you're feeling and seeing where your stance is in that situation."

2. "I think dealing with anyone in your work environment whether it be the patient, the patient's family, maybe if they're really upset and they can't make a decision about what they want to do ... seriously ill patient, you could say. . . 'are you feeling this way because?' . . and maybe help level them out a little bit."

3. "Maybe a really stressed doctor you want to get a point across...I guess in different ways in all the communication that you have with everyone."

4. "I think it would help out a lot. . . in situations where the patient would talk to the nurse like, 'oh I thought I was going to get this specific type of nurse. Why are you here?' Or, like 'oh, well I want a doctor because nurses don't know what they're talking about.' So I think that would help out a lot, because I would feel insulted by that, but using NVC it would be like 'oh, okay, maybe this is why they're feeling this way,' so I don't take it personally."

5. "In addition to patients, I see, although I haven't been in clinicals yet, I see the relationship between nursing student and a clinical instructor as really important. It's really vital, and associated with learning and so forth, and really is an introduction to what it's like to work under someone as a nurse. And I see NVC as a great way of maintaining and keeping that healthy relationship."

What obstacles have you experienced using NVC?

1. "The guessing part can be kind of difficult, just because like sometimes you're not really on point with that. But then it does also help that person figure out like 'no, I'm not feeling this, but I am feeling this."'

2. "For me it was asking a person, 'oh, what are you feeling?' They're like, 'what?' It's weird."

3. "I think the hardest part is just recognizing that I can use it and I do know what I'm talking about."

4. "You know, it's applying it. I think is the hardest part in the moment."

5. "I think it's hard to make myself kind of vulnerable."

6. "A lot of the examples that we used in class were an equal sharing, back and forth conversational thing and I don't know that I would probably feel comfortable talking to a patient in that way."

7. "I haven't really found the need to use it yet. I mean it's a good tool to have, but I haven't really recently come into any problem."

8. "I wasn't sure how I would handle it if someone was not willing to listen at all, because... if they're just completely cut off from you, I feel like I would feel helpless in that situation."

9. "I kind of feel kind of weird when I was saying to someone, 'oh, you're probably feeling like this ... because I feel like it's really obvious that I'm using something."

10. "...A hard part is, like figuring out their needs, but not being able to do anything about it."

11. "I think like sometimes [it's] overwhelming. I'm not really sure how I'm feeling or what I need."

12. "Making a request ... I think that's one of the hardest things to do."

13. "I know this is a way of resolving conflict. I don't like to initiate conflict, so I'm kind of pressured about it but let it go because I only open a can of worms type of thing." 


\subsection{Professional experiences}

The two focus groups that were conducted 2 years post training aimed to evaluate NVC's usefulness in the clinical settings given that during the training most of the students had not yet begun their clinical rotations. However, when asked the general question: "How has NVC been useful to you since the training?" students gave a range of situations, including, but not exclusive to patient or clinical settings, where they had relied upon their NVC knowledge since the training. The following narratives were chosen as key professional exemplars to further demonstrate NVC's broad applicability in enhancing empathic communication.

\subsubsection{Working with children: "No one's really listening to them"}

One student shared the successful use of NVC while working as a church youth counselor. Parents of a young boy asked if he would talk to their son because they were concerned about some of his recent behaviors. The student summarized his story with: "And so just using that non-violent communication to build up that trust, to have that friendship with him, [helped] him feel secure in like [conversing] with me..." This student found himself in a situation where he was able to draw on NVC to develop trust, a strategic component of empathic communication in order to effectively impact a change in behavior.

Another student described how she used NVC working with elementary school kids who have "a lot of behavioral problems" with parents who are in jail, etc., and that most of the teachers "just kind of yell." She elaborated on how NVC helped her: "I realized what really helps is to get to their level, and see what their needs are, and kind of communicate from there. And it really helps to calm them down and make it not so chaotic." An invaluable component of NVC when dealing with others who are exhibiting adverse behaviors is to investigate what needs are not being met. This student shared how the attempt to gain the others' perspective by just listening had a calming effect on the children.

\subsubsection{Working with patients: "I t's all about empathy"}

The following narrative accounts were taken from the students reflecting the experienced use of NVC while working with patients. Many students affirmed the effectiveness of using elements of NVC especially in psychiatric units. Others shared in more general terms.

Regarding a half-way house where one student was working, NVC was described as a great tool to assess where patients were emotionally on any given day. She shared: "I kind of used it as a way to [determine] how I would approach them and how I would talk to them, and how I would see how they were doing, but kind of like a filter before I would initiate conversation." This demonstrates the ability to employ NVC as a means to understand the status of unstable patients. This has the potential to greatly impact the smoothness of the interaction between nurse and patient.

This following narrative clearly portrays how NVC was used during the student's psychiatric rotation with patients who are "at their most emotional vulnerable." This male student spoke of the challenges in conducting a psych history, and elaborated:

... So, Nonviolent Communication kind of helps [when] patients are transferring their frustrations on us... And using that empathy of saying, "Hey, I see that you're stressed out, but I want to help you more. Let's focus all this energy that you have towards exploring different ways for us to help you," allows us to kind of redirect the question back to them, and allow them to explore different parts of themselves that they weren't able to address before.

Students are often intimidated in psychiatric clinicals. Here we see how this student has identified how empathy exhibited in a concrete way enables the student to calm the patient, and encourage the patients' self discovery which inevitably enables the student to accomplish his objectives. 
The following student expressed the most enthusiasm about NVC, but captures the keenness of many other students. She gave this overall accolade:

The Nonviolent Communication teachings have proven to be one of the most valuable things I have learned in nursing school thus far. I use it daily, if not more, in my personal life as well as in clinicals and at work. These tools have completely changed how I interact with people and I think have changed the way people view me as a confidant, friend, and professional.

She then shared specific examples of how learning NVC has benefited her in patient settings.

I used the NVC tools the most last semester when I had my psychiatric clinical rotation... I was so thankful to have my training in NVC to help me through talking to patients about these tough topics. During these interviews I was able to say simple things like, 'That must have been really difficult and stressful for you,' or 'It sounds like you're feeling overwhelmed and need some support,' that patients were able to connect with. Typically when I say something along those lines whether it be during clinical or in my personal life, people react with, 'Yes! Exactly!' It feels so good to know that I'm interacting with people in the way that they need.

The enthusiasm shared by this student captures the potential for NVC in enhancing connection with others and for meeting her own human need for celebration as she articulately summarized in her last sentence. Her level of confidence was raised in knowing she had a tool to use in tough clinical situations and the confirmation of her ability to positively impact others through the simple act of empathic reflection is empowering.

This next student also shared his comment with zest, but rather in a matter of fact manner while reflecting on the use of NVC in the psychiatric setting.

...Empathy is the key to it, -- looking outside of yourself and trying to find some core connection with the person, and through communication, get to that part. And I find that where I work, this is just how you exist because I work in a psychiatric unit. You have to do this constantly because if you don't, then it just escalates even further. So, Nonviolent Communication, I think it's just a natural way of existing within the healthcare system because eventually, you're going to run into these issues, and you're going to have to be able to empathize. I think empathy is the main thing. It's been said already, but that's what we're going to do, that's it.

This student was adamant that empathy is a cornerstone of patient care, and that NVC is one tool to enable a nurse to empathize. He is convinced that not only is this skill imperative to function in a psych unit but within healthcare overall. He spoke with confidence that one has to hone their empathy skills, and the ease in which NVC may be applied to accomplish this affirms its concrete usefulness in the broader healthcare system.

The many examples above showed how versatile NVC can be when applied whole or in part, with different people in different situations. Furthermore, positive experiences of using it in patient settings demonstrate its specific usefulness in enhancing nurse-patient communication, and therefore supporting its potential for improving patient care overall. Some challenges in using NVC are described below.

\subsection{Challenges}

Students shared challenges they had with using Nonviolent Communication in some settings. Table 3 includes responses to the question: "What obstacles did you experience in using NVC?" Fear of vulnerability in situations where there may be a power imbalance such as with a manager or boss was raised. Difficulty in changing the way one is accustomed to doing things was also expressed. However, most examples of challenges appeared to reflect students' inexperience in understanding or using NVC accurately. For example, one student shared that it would be hard to talk to patients using 
NVC, whereas it was easier to do it with his girlfriend because there is a mutual sharing of feelings and needs. The understanding that the particular elements of NVC can be used in different ways was not clearly comprehended.

Some shared that it was difficult to guess what others were feeling or needing, but acknowledged the importance of doing that. Some found it uncomfortable making requests. When asked about the challenges, this student relayed: "The request, I think. Like I kind of understood it in class, but just how it would be done in like a real situation....like my person was, like, well, what are you doing?" This student shared how practicing in class is different than doing it in a real life situation and portrays the awkwardness of employing a new technique especially when it comes to a new way of communication where habits are so ingrained in one from early childhood.

Another point that was raised by a student is the challenge that occurs when one needs to initiate the conversation. This student is one who most likely would rather a problem go away on its own rather than approach someone. She elaborates:

I know this is a way of resolving conflict. I don't like to initiate conflict, so I'm kind of pressured about it but lets it go because I only open a can of worms type of thing. Or, I really should talk to my teacher about my grade but, maybe he's going to give me a lower grade because I want to talk to him.

The fear that approaching someone about a conflict may exacerbate the problem rather than solve it, is reflected in this student's comment. Avoidance may not always be the best solution and this student may need assistance in building confidence and self efficacy in order to develop non threatening means of getting her and her patients' needs met.

The following student shared her hesitancy using NVC with someone of a higher position than she:

I think in most situations when I'm dealing with someone that really angry or upset I tend to just agree and say okay, okay. But it's taking that step to like probe them and see if you can do something, and you are kind of putting yourself out there if you're not right. And see, we don't want to make them more angry or something like that.

This student also reflects intimidation, but most likely this is due to inexperience in effective communication during a conflict situation. Over time her confidence and assertiveness could be built with the successful and accurate use of communication tool such as NVC.

Although challenges to using NVC had been shared by the students, qualitative findings demonstrate that the overall majority had expressed its benefit in enhancing empathy of self, and of others in personal and professional settings, including while working with patients. An appreciation for having learned a concrete communication tool to use in various settings was supported by the narrative data. In addition, most of the these exemplary stories reflected an increase in empathy, as evidenced by an ease or newfound skill in employing cognitive capabilities and empathic concern to identify and understand emotions in self and others, and to regulate emotions in self in order to manage conflict, or de-escalate potentially unstable situations and/or patients.

\section{Discussion}

This was the first mixed methods pilot study testing the impact of a Nonviolent Communication training on nursing students in the classroom setting. Quantitative results revealed an increase in empathy post training. Findings from the qualitative analyses demonstrated the positive impact of NVC on the ability to empathize with self and others with a special emphasis on working with patients during psychiatric rotations.

Student narratives exhibit a growth in cognitive and affective constructs measured in the IRI - the ability of one to adopt others' perspectives, and one's ability to feel warm, compassion, and concern for others who are undergoing negative experiences ${ }^{[32]}$. Overall, students scored high in empathy as measured by the IRI. Students' pre- mean scores for all subscales are 
considered higher than means reported by Davis in original psychometric studies ${ }^{[32]}$. The attrition rate of $24 \%$ is mainly attributed to the decease in attendance toward the end of the semester since students were administered the survey in their regulary attended professional nursing course.

The increase in empathy demonstrated in this study supports findings by Marlow et al. ${ }^{[25]}$ in the use of NVC with formerly incarcerated adults. After receiving NVC training, mean scores on the BEES tool measuring empathy were increased; in addition, participants' narratives described increases in the ability to listen to others, an awareness of others' feelings, and the sense of interpersonal connection. All of these experiences were reported in the current study, and gives promise for more successful and satisfied personal and professional lives for future nurses.

An inability to demonstrate an increase in empathy as measured by the IRI was reported by Webster ${ }^{[21]}$ in a study examining the impact of reflective journaling during nursing students' psychiatric clinical rotation. Participants in the current study scored similarly in the IRI subscales as those in Webster's study, with highest scores noted in the area of Empathic concern. Moreover, Webster reported that qualitative data revealed an increase in the students' ability to focus on their patients' concerns ${ }^{[21]}$. This increase in empathic concern was repeatedly demonstrated in the narratives of the current study in interactions with others in multiple situations, including the accounts portrayed by the students during their psychiatric rotations and work settings. What this study further provides is support for a tool beyond just journaling to give students a concrete method to incorporate into their practice that could feasibly enhance their empathic interactions with patients. A training that may have an impact on empathic concern is worthy of further investigation since a decrease in empathic concern had been found in college students from 1979 to $2009^{[39]}$.

Cunico and colleagues ${ }^{[20]}$ have also demonstrated an increase in empathy in nursing students through the incorporation of a special training when compared to those who did not receive the training. However, they found that the intervention had a greater impact on female versus male students ${ }^{[20]}$. In the current study, gender differences were also noted with females scoring higher in empathy both pre and post training. As more males enter the nursing workforce, this finding may be particularly worthy of exploration, as it may be possible that social influences on gender expression of empathy would impact male nurses disproportionately.

The stories shared in this study demonstrated ways that the students incorporated NVC to arrive at new understandings of others' emotions and needs, which resulted in de-escalation of tense situations, and a calmness in others, as well as their own sense of self efficacy in their roles as friends, teachers, and nurses. This nurtures a sense of collegiality and authenticity through empathic communication instead of the reactionary default of individualistic and self-serving methods that inevitably lead to a downward spiral of ineffective validation and unmet needs for all parties involved ${ }^{[31]}$. This increased ability to de-escalate tense situations is invaluable in clinical situations working with colleagues and reflects a higher level of empathic connection with self and others. Ditmer ${ }^{[42]}$ provided a shocking exposé of horizontal violence among nurses and emphasized the need for effective training programs to help nurses learn to reflect and regulate emotions that easily arise in stressful unit situations. Instead of harsh and cruel means that perpetuate interpersonal conflict and ultimately jeopardize patient safety and wellbeing ${ }^{[42]}$, NVC may be one way to foster collegiality and nonviolent problem solving in nurses.

\section{Limitations}

This mixed method pilot study used a quasi experimental design which has its own innate limitations. Using a control group would have increased the internal validity of the study. However, due to the close ties within a cohort of nursing students, contamination of the intervention would have been inevitable. The incorporation of a similar group of students in another university may have been the only way to include a control group. Recruiting students as participants in educators' research may risk a felt sense of coersion by the students. However, since this research was not conducted with the PI's students and that the instructor of the course was unaware of who was participating, coersion was reduced if not eliminated. Further research is recommended to add to this preliminary study. 


\section{Conclusion/ implications for nursing}

Any method that could enhance empathy among nursing students is worthy of consideration. As nursing students take on more responsibilities and begin to focus more on tasks, empathy has been found to decrease ${ }^{[43]}$. An emphasis on empathic concern for self and others, and clear, solid tools for nurses to employ in various situations would maintain channels of communication with coworkers and patients alike, and could in turn reduce stress and hardship, increase job satisfaction, and stimulate effective leadership in healthcare. Further research may be needed to capture the larger impact that Nonviolent Communication could have on nurses and nursing students. However, this mixed method study demonstrated the potential for a simple, concrete tool for nurses to use to enhance empathy, previously found to positively impact the workplace ${ }^{[33]}$. Incorporating reflective knowledge into nursing education in a professional nursing or leadership course could feasibly prevent future hardship as students advance their nursing careers ${ }^{[44]}$. Moreover, efforts must be made in nursing education to inspire empathy toward self and other, and to nurture mutuality and respect, core values of nursing and transformative education ${ }^{[18,27]}$.

\section{Acknowledgements and funding}

The researchers would like to acknowledge Carol Chase and Tony McFarlane for their expert, compassionate, and dedicated NVC teachings and for the support of the University of San Francisco School of Nursing and Health Professions Faculty Development Funds.

\section{References}

[1] Buerhaus P, Donelan K, DesRoches C, Hess R. Still making progress to improve the hospital workplace environment? Results from the 2008 National Survey of Registered Nurses. Nurs Econ. 2009; 27(5): 289-301. PMid:19927444

[2] Institute for Safe Medication Practice. Intimidation: practitioners speak up about this unresolved problem. [Internet] 2004. Available from: http://ismpd.org/Newsletters/acutecarearticles/20040311_2.asp?ptr=y. Accessed December 2009.

[3] Page A, ed. Keeping patients safe: Transforming the work environment of nurses. [Internet] Institute of Medicine. Committee on the Work Environment for Nurses and Patient Safety. Washington, DC: National Academy Press; 2004. Available from: http://www.nap.edu/openbook.php?isbn=0309090679

[4] Joint Commission. Improving hand off communications. [Internet] 2007. Available at http:www.jcipatientsafety.org/15427

[5] Rothschild JM, Landrigan CP, Cronin JW. Kaushal K, Lockley SW, Burdick E, et al. The Critical Care Safety Study: The incidence and nature of adverse events and serious medical errors in intensive care. Crit Care Med. 2005; 33: $1694-1700$. PMid:16096443 http://dx.doi.org/10.1097/01.CCM.0000171609.91035.BD

[6] Kelly J. An overview of conflict. Dimens Crit Care Nurs. 2006; 25(1): 22-28. http://dx.doi.org/10.1097/00003465-200601000-00007

[7] Weiss J, Hughes J. Want collaboration? Accept and actively manage conflict. Harv Bus Rev. 2005; 3(3): 92-101.

[8] Tabak N, Koprak O. Relationship between how nurses resolve their conflicts with doctors, their stress and job satisfaction. J Nurs Manag. 2007; 15: 321-331. http://dx.doi.org/10.1111/j.1365-2834.2007.00665.x

[9] Keenan KM, Cooke R, Hillis SL. Norms and nurse management of conflicts:Keys to understanding nurse-physician collaboration. Res Nurs Health. 1998; 21:59-72. http://dx.doi.org/10.1002/(SICI)1098-240X(199802)21:1<59::AID-NUR7>3.0.CO;2-S

[10] Sexton B, Makary M, Tersigni A, Pryor D, Hendrich A, Thomas E. Teamwork in the operating room: frontline perspectives among hospitals and operating room personnel. Anesthesiology. 2006; 105(5): 877-884. http://dx.doi.org/10.1097/00000542-200611000-00006

[11] Thomas EJ, MD, Sexton JB, Helmreich RL. Discrepant attitudes about teamwork among critical care nurses and physicians. Crit Care Med. 2003; 31(3): 956-959. http://dx.doi.org/10.1097/01.CCM.0000056183.89175.76

[12] Zwarenstein M, Goldman J, Reeves S. Interprofessional collaboration: effects of practice-based interventions on professional practice and healthcare outcomes. Cochrane Database Syst Rev. 2009; 3.

[13] Benson G, Ploeg J, Brown B. A cross-sectional study of emotional intelligence in baccalaureate nursing students. Nurs Educ Today. 2010; 30: 49-53. http://dx.doi.org/10.1016/j.nedt.2009.06.006

[14] Beauvais AM, Brady N, O'Shea ER, Quinn. Emotional intelligence and nursing performance among nursing students. Nurs Educ Today. 2011; 31(4): 396-401. http://dx.doi.org/10.1016/j.nedt.2010.07.013

[15] Heffernan M, Griffin M, McNulty S, Fitzpatrick J. Self-compassion and emotional intelligence in nurses. Inter J Nurs Pract. 2010; 16(4): 366-373. PMid:20649668 http://dx.doi.org/10.1111/j.1440-172X.2010.01853.x 
[16] Kristjansdottir G. Empathy: A therapeutic phenomenon in nursing care. J Clin Nurs. 1992; 1: 131-140. http://dx.doi.org/10.1016/j.nedt.2010.07.013

[17] Jolliffe D, Farrington DP. Empathy and offending: A systematic review and meta-analysis. Aggress Violent Behav. 2004; 9:441-476. http://dx.doi.org/10.1016/j.avb.2003.03.001

[18] Williams J, Stickley T. Empathy and nurse education. Nurs Educ Today. 2010; 30: 752-755. doi:10.1016/j.nedt.2010.01.018

[19] Brunero S, Lamont S, Coates M. A review of empathy education in nursing. Nurs Inq. 2010; 17: 64-73. http://dx.doi.org/10.1111/j.1440-1800.2009.00482.x

[20] Cunico L, Sartori R, Marognolli O, Meneghini A. Developing empathy in nursing students: A cohort longitudinal study. J Clin Nurs. July 2012; 21(13/14): 2016-2025. PMid:22672461 http://dx.doi.org/10.1111/j.1365-2702.2012.04105.x

[21] Webster D. Promoting empathy through a creative reflective teaching strategy: A mixed-method study. J Nurs Educ. 2010; 49(2). PMid:19810667 http://dx.doi.org/10.3928/01484834-20090918-09

[22] Rosenberg, MB. Nonviolent communication: A language of life (2nd Edition ed.). Encinitas: Puddle Dancer Press; 2005.

[23] Rosenburg, MB. Speak Peace in a world of conflict. What you say next will change your world. Encinitas: Puddle Dancer Press; 2005.

[24] Lee CA, Kessler D, Varon D, Martinowitz U, Heim M, Rosenburg M, Molho P. Nonviolent empathic communication for health care providers. Haemophilia. 1998; 4(4): 335-340. http://dx.doi.org/10.1046/j.1365-2516.1998.440335.x

[25] Marlow E, Nyamathi A, Grajeda WT, Bailey N, Weber A, Younger J. Nonviolent Communication (NVC) training and empathy in male parolees. J Correct Health Care. 2012; 18(1):8-19. PMid:22095007 http://dx.doi.org/10.1177/1078345811420979

[26] Dzaferovic, M. Nonviolent Communication, empathy and assertion as modern strategies in the study of overcoming conflicts. Metodicki obzori. 2012; 7: 105-116.

[27] Koegel R. Partnership education and Nonviolent Communication [Internet]. Encounter: Educ Meaning Soc Justice. 2002; 15(3): 2-4. Available from: http://www.nonviolentcommunication.com/pdf_files/partnership_education_rkoegel.pdf

[28] Latini, TF. Nonviolent Communication: A humanizing ecclesial and educational practice [Internet]. J Educ Christian Belief. 2009; 3: 19-31. Available from: http://www.luthersem.edu/leadingfromtheheart/nvc_as_humanizing_practice.pdf

[29] Chung H, Kim S. Effects of a Nonviolent Communication Program for Hospital Nurse Managers in Korea. Paper presented at: Sigma Theta Tau 22nd International Nursing Research Congress; 2011 July 11-14; Cancun, Mexico

[30] KÖK H. Nonviolent Communication in Political Conflicts [Internet]. USAK Yearbook International Politics and Law. 2009; 2:349-362. Available from: http://www.usak.org.tr/images_upload/files/makale17_2009.pdf

[31] Nosek M. Nonviolent Communication: A dialogical retrieval of the ethic of authenticity. Nurs Ethics. 2012; 19(6): 829-837. http://dx.doi.org/10.1177/0969733012447016

[32] Davis MH. A multidimensional approach to individual differences in empathy [Internet] JSAS Catalog of Selected Documents in Psychology. 1980; 10:85. Available from: http://www.uv.es/ friasnav/Davis_1980.pdf

[33] Gunther M, Evans G, Mefford L, Coe TR. The relationship between leadership styles and empathy among student nurses. Nurs Outlook. 2007; 55: 196-201. http://dx.doi.org/10.1016/j.outlook.2007.01.013

[34] Sitzman, K. Anger and the use of Nonviolent Communication. Home Healthcare Nurs. 2004; 22(6): 429. http://dx.doi.org/10.1097/00004045-200406000-00017

[35] Benner P. Interpretive phenomenology: Embodiment, caring and ethics in health and illness. 1994. Thousand Oaks: Sage

[36] van Manen M. Researching the lived experience. 1990. Albany: State University of New York Press.

[37] Erdfelder E, Faul F, Buchner A. GPOWER: A general power analysis program. Behav Res Methods Instr Computers.1996; 28: 1-11. http://dx.doi.org/10.3758/BF03203630

[38] Davis MH. A multidimensional approach to individual differences in empathy. JSAS Catalog of Selected Documents in Psychology. 1980; 10: 85.

[39] Konrath SH, O'Brien EH, Hsing C. Changes in dispositional empathy in American college students over time: A meta-analyses. Pers Soc Society Psych Rev. 2011; 15(2): 180-198. PMid:20688954 http://dx.doi.org/10.1177/1088868310377395

[40] Yu J, Kirk M. Measurement of empathy in nursing research: Systematic review. JAN. 2008; 64(5): 440-454. PMid:19146512 http://dx.doi.org/10.1111/j.1365-2648.2008.04831.x

[41] Bellini LM, Baime M, Shea JA. Variation of mood and empathy during internship. JAMA. 2002; 287(23): $3143-3146$. PMid:12069680 http://dx.doi.org/10.1001/jama.287.23.3143

[42] Ditmer D. A safe environment for nurses and patients: Halting horizontal violence. J Nurs Regul. 2010; 1(2): 9-14.

[43] Cody WJ, Schaal M, Hojat M. The empathy enigma: An empirical study of decline in empathy among undergraduate nursing students. J Prof Nurs. 2012; 28: 34-40. http://dx.doi.org/10.1016/j.profnurs.2011.10.007

[44] Horton-Deutch S, Sherwood G. Reflection: an educational strategy to develop emotionally competent nurse leaders. J Nurs Manag. 2008; 16: 946-954. http://dx.doi.org/10.1111/j.1365-2834.2008.00957.x 